\title{
Celiac Disease Seen with the Eyes of the Principle Component Analysis and Analyse Des Données
}

\author{
Cleto Corposanto ${ }^{1 *}$, Beba Molinari², Susanna Neuhold ${ }^{3}$ \\ ${ }^{1}$ Dipartimentodi Scienze Giuridiche, Storiche, Economiche e Sociali, Università Magna Graecia di Catanzaro, \\ Catanzaro, Italy \\ ${ }^{2}$ Dipartimento di Scienze della Formazione, Università degli Studi di Genova, Genova, Italy \\ ${ }^{3}$ Food Area National Manager, Associazione Italiana Celiachia, Genova, Itay \\ Email: ${ }^{*}$ cleto.corposanto@unicz.it, beba.molinari@unige.it, sneuhold@celiachia.it
}

Received 21 January 2015; accepted 22 April 2015; published 28 April 2015

Copyright $(2015$ by authors and Scientific Research Publishing Inc.

This work is licensed under the Creative Commons Attribution International License (CC BY).

http://creativecommons.org/licenses/by/4.0/

(c) (i)

\section{Abstract}

This paper aims to deepen the quality of life of people with celiac disease with a focus on compliance to the diet through Principle Component Analysis and Analyse des Données. In particular, we will try to understand whether these analyzes are also applicable in the context of research web2.0 carried out with web-survey.

\section{Keywords}

Celiac Disease, Web-Survey, Principle Component Analysis, Analyse Des Données

\section{Introduction}

The scope of this article is to present the findings of a web-survey conducted over two editions (2011-2013) on how sufferings of celiac disease relate to everyday life, from socialisation to quality of life. For compliance we intend the "level with which the action or behaviour of a person coincides with the advice or prescription of a social-medical professional to prevent, monitor or treat a disorder" [1]. We can distinguish two main macro objectives, the first taking into consideration the results of the research, i.e. understanding compliance with a deliberate diet and a pathology that increasingly appears in everyday language, even among non-celiac suffers who see the shelves of supermarkets, pharmacies, school canteens, hospitals, restaurants and advertising offering ever-increasing amounts of gluten-free food.

"Corresponding author.

How to cite this paper: Corposanto, C., Molinari, B. and Neuhold, S. (2015) Celiac Disease Seen with the Eyes of the Principle Component Analysis and Analyse Des Données. Open Journal of Statistics, 5, 211-222.

http://dx.doi.org/10.4236/ojs.2015.53023 
The second macro objective defined in relation to typically more methodological aspects concerns the use of a web-survey platform and how it can contribute to understanding such a vast social phenomenon as celiac disease, trying to reflect on the validity of the tool compared to a pencil \& paper questionnaire and instead, to what extent it can be considered an alternative tool to exclusively measure the ongoing dynamics developing on the web 2.0.

Therefore, investigating poor adhesion to a “chosen”, deliberate diet means in our context of research reconstructing a theoretical and equally analytical scenario based on the needs and issues involved in a gluten-free diet, to purposefully define the strengths and weaknesses of living with celiac disease on a daily basis. Such content-related objectives guided the research team to define the useful variables for the study.

\section{Methodology}

The dynamics that will be analysed in the following paragraph are the results of an online survey that involved the participation of 5001 celiac sufferers between the first and second edition, which took place respectively in 2011 with 3001 participants and in 2013 with 2853 interviewees. The sample, represented at regional level for both surveys is entirely in line with findings in the two Annual Parliamentary Reports published by the Ministry for Health in the years relevant to the research (2011-2013).

Thanks to the use of the online platform, capillary distribution of the questionnaire was possible at national level within a reduced timeframe: in fact, the administration period was just two months, from the end of November 2011 to the end of January 2012 and from December 2013 to January 2014.

With reference to the response trend, break-off and drop-out was respectively around 20\% and 15\%, with break-off intended as established in the report by the American Association for Public Opinion Research (AAPOR) [2] which not only states the methods to distinguish between total and partial interviews, but proposes five different calculation methods to analyse the rate of response, cooperation, refusal and contact. These standard definitions are indicated for person to person surveys, in named person postal surveys and for cati, i.e. for all those surveys that have the possibility of knowing the names of the respondent, the reason for which we have decided to use these rates, given we had the opportunity during our research to know the exact number of respondents, the purpose is to understand how much these measures can also be valid in web 2.0 contexts.

However, it is not possible to discuss the response trend without a first brief presentation of the semi-structured type questionnaire, which includes some questions with skip logic (online compilation facilitated and reduced the margins for compilation error to a minimum), with a prevalence of closed questions and with only $10 \%$ open questions, useful to specify certain considerations that require personal explanation relating to the medical treatment undertaken and the difficulties encountered to diagnose one's illness. The variables are mainly categorical, ordinal and some cardinal, giving a total of approximately 50 variables (Figure 1).

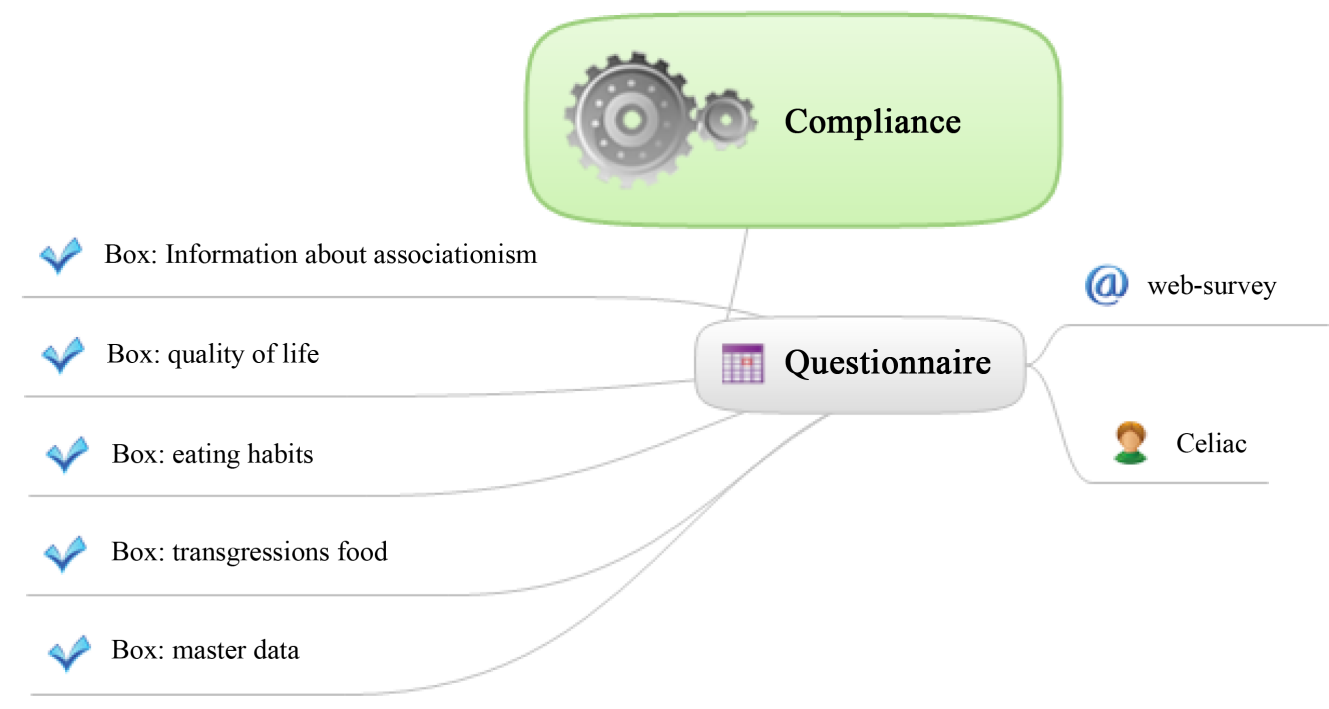

Figure 1. The questionnaire. 
The study analysed different issues, always in reference to dietary compliance, in its various aspects, from social life to dietary habits. The questionnaire is divided into four distinct sections of a cognitive nature and a final section that analyses the interviewees' personal details: from a series of questions that try to investigate the relations celiacs have with the Italian Celiac Association (AIC) ${ }^{1}$, we move onto a series of questions on the quality of life they have and their dietary habits. Lastly, a fourth section, considered the heart of the study, is dedicated to investigating the area of compliance with a gluten-free diet, as is the measurement with which celiac sufferers transgress, knowingly or unknowingly.

This new form of on-line administration can in fact be fully inserted among the CAWI and in the self-administrating category of questionnaires requiring no assistance [3] [4], where, however, the interviewee interfaces directly with the computer using an internet connection. We therefore tried to ensure the questionnaire did not take more than 40 minutes to complete, and that its compilation was as clear and intuitive as possible. For this reason, semi-structured and Likert scale [5] [6] questions were preferred, with open questions limited to a minimum.

\section{What Dietary Habits Have Celiac Sufferers?}

Here, we will only analyse certain aspects of the 50 items studied in this research using synthesis as the principle component analysis (pca) and the Analyse des Données to further study the risk [7] [8] and therefore dietary transgression (Figure 2). We will try to define the quality of life and therefore the level of overall wellbeing perceived by those who live on a daily basis with chronic illness for which no cure exists, unless you abstain from eating foods containing gluten.

We will now present some general information based on the sample traits: An overview sees the average age of the interviewees being 32, with a maximum age peak of 80 and where 38 years old are distinguished as being the most frequently present (73 people). The latter confirm the fact the age group between 38 and 57 years of age is the most represented (37.1\%) together with the previous age group, 19 - 37 year olds, with a $38.9 \%$ percentage, where $41 \%$ of the entire sample have an average-high education.

In relation to the personal details linked to gluten intolerance, it would now appear that women are most affected by the disease in Italy. The data presented to Parliament highlight a constant trend in the two years of 71\% of women diagnosed compared to $29 \%$ men. We found a gender difference of just 8 percentage points: $79 \%$ celiac women compared to $21 \%$ celiac men [9].

Instead, data that cannot be compared with institutional statistics, yet extremely interesting when one considers quality of life pre and post diagnosis, is the average time a person is aware of their intolerance to gluten. It

Are you tempted by the transgression? Percentages

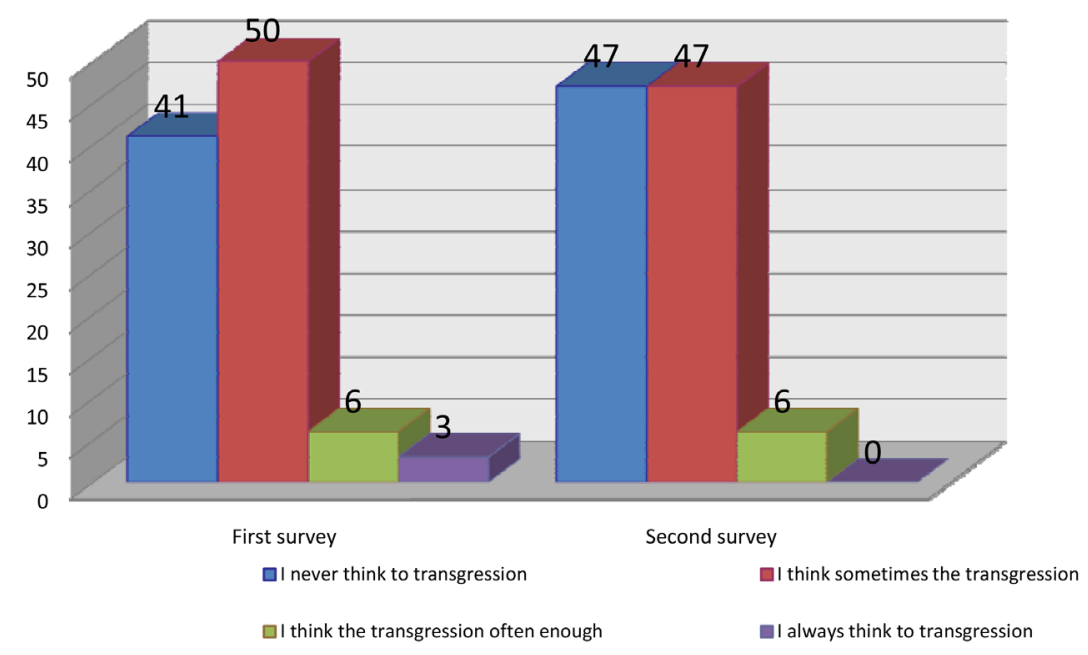

Figure 2. How many ties a day a celiac sufferer thinks about dietary transgression-survey 20112013-Percentage values.

${ }^{1}$ For further information on the mission of the Italian Celiac Association, consult the following link: http://www.celiachia.it/AIC/Aic.aspx. 
emerges that those interviewed were diagnosed on average for 6 years, despite the fact $20 \%$ of those interviewed only became aware of their illness in the last year.

Let's take a step back and chart some additional information within the personal data to highlight half the participants are married and/or cohabiting, 38\% have at least one child and just over half of the sample are employed (57.4\%), while 34\% have a monthly salary between 1000 and 2000 euro.

Having pointed out the sample profile, we can now move onto the results where we highlight $1 / 6$ of the interviewees admit to breaking their diet at least once a month in both studies.

The results of the surveys are substantially identical. $89 \%$ of the interviewees did not consume food outside their gluten-free diet, with a variance in favour of the second survey of 3 hundred of a point. From the joint reading of what emerges from the question on dietary habits in the last month and the temptation to transgress, a grey area remains which was already discussed in the previous survey: given $14 \%$ declared they have transgressed once in the last month, while $47 \%$ declared they think about it every now and then, we can assume that a grey area exists of about $33 \%$. We would like to understand the reasons encouraging people not to go off their die (Figure 2).

In this respect, we would like to highlight the grey area went from $37 \%$ to $33 \%$, with a variance of 4 percentage points, confirming that greater awareness exists in living with one's celiac condition. Losing 4 percentage points in 2 years is an excellent result because it involves habits and social conventions that are difficult to abandon.

The number of those breaking their diet a few times a month has increased, from $32 \%$ to $37 \%$, while multiple times a month remains constant (7\%). Here, we have a first alarm bell, given that what we have analysed up to now gives the impression celiac sufferers are more aware of the risks and problems caused by not following their diet exactly, however the attention threshold has lowered slightly.

Before further analysing the observations, we would like to define what we consider "risk", as defined by Luhmann [8] according to whom showing risky behaviour is a conscious decision given by a social factor within a decision making process, therefore we have tried to analyse, through an Analyse des Données and pca the common traits that contribute to defining possible sub-groups.

We begin with the technical Analyse des Donées re-evaluated by Benzécri in the Sixties [10] [11], thanks to which it is possible to analyse the categorical variables using Spad software that enables distinction between variables-active category, that directly contribute to the formation of factorial axes, and variables-illustrative category, not contributing to factor formation, although useful in interpreting the latter. The procedure involved the following steps. Firstly an analysis was conducted on the main components (CORMU) followed by the procedure for simplified interpretation of the factors produced by the acm (Defac), which allowed us to set the number of factors to represent, as well as describe the elements in absolute terms. Lastly, to activate the cluster procedure, which in the language used by Spad is called Recip/Semis, the Semis analysis was chosen which is preferred to the previous in analyses with a substantial number of cases, since: "it avails of a mixed category that produces a hierarchic, ascending classification using Ward's criteria on the results of a previous non-hierarchic aggregation completed on three, previous defined mobile centres” [12]. Thanks to a previous procedure, it is possible to have the maximum of the economy in the representation of the research results. In fact, from the analysis three distinct groups emerged that are attributable to the age factor and therefore to the different lifestyles: minors, young adults and adults 4 .

Among the three sub-groups Figure 3, those distinguished as being more at risk in gluten consumption are young adults with a medium and medium-high academic qualification, some seeking employment for the first time, others employed but with part-time work. In fact, they break their diet more frequently and show major signs of transgression compared to the other age groups in the sample, while minors tend to follow their diet more carefully and transgress less.

We can now move on to illustrate what emerges from the two analyses conducted using the pca technique to reconstruct certain elements in more detail that could not be analysed with the categorical variables involved in the previous analysis formulation, focusing attention on the one hand, in the first pca on behaviour in everyday life, while in the second focusing on more food-related aspects.

Thanks to the pca, it is therefore possible to summarise a series of cardinal variables which are correlated through the identification of their 105 principle components, in this case conducted thanks to SPSS software support [13]-[15].

Were required the following commands to SPSS (Figure 4): 


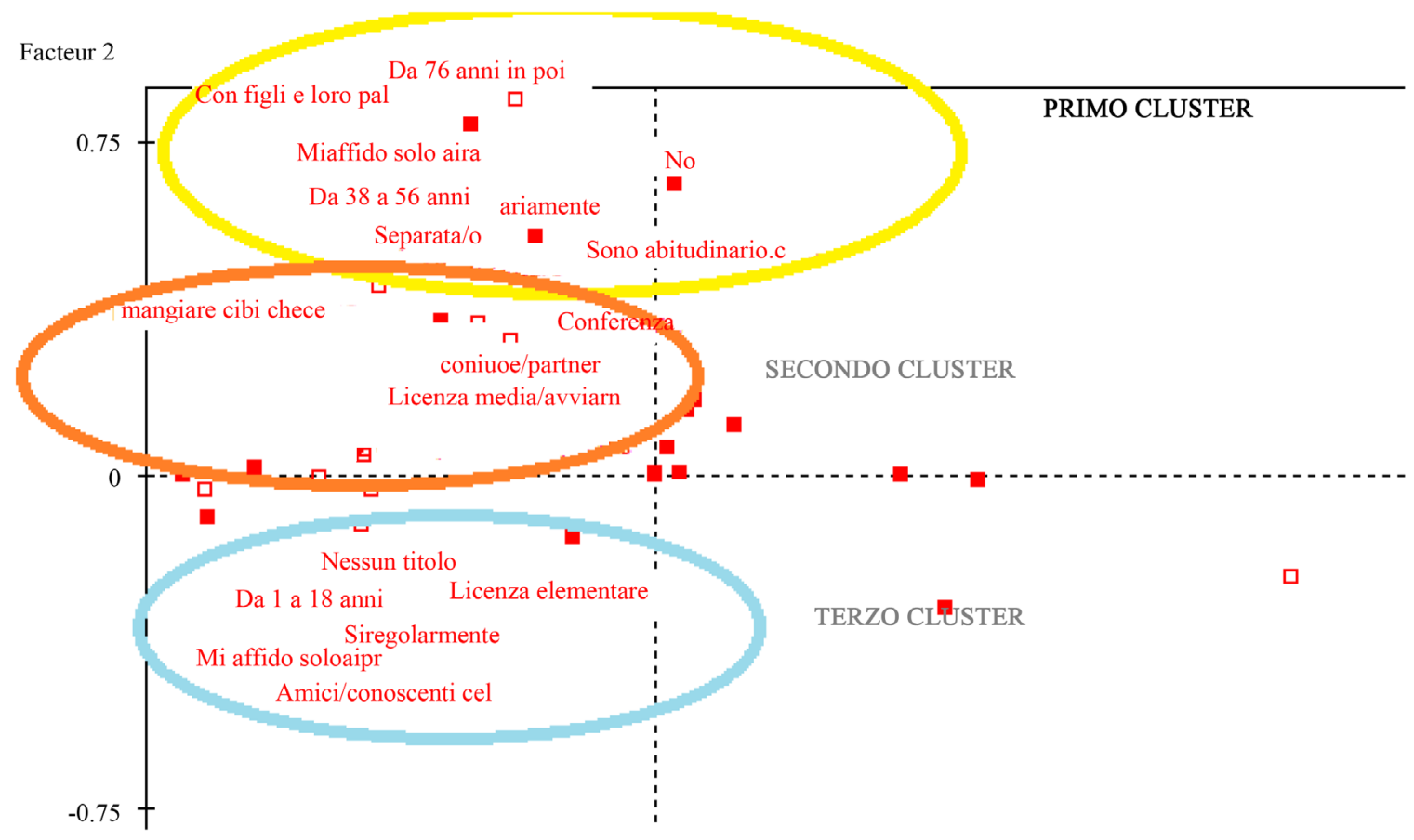

Figure 3. Analyse des données.

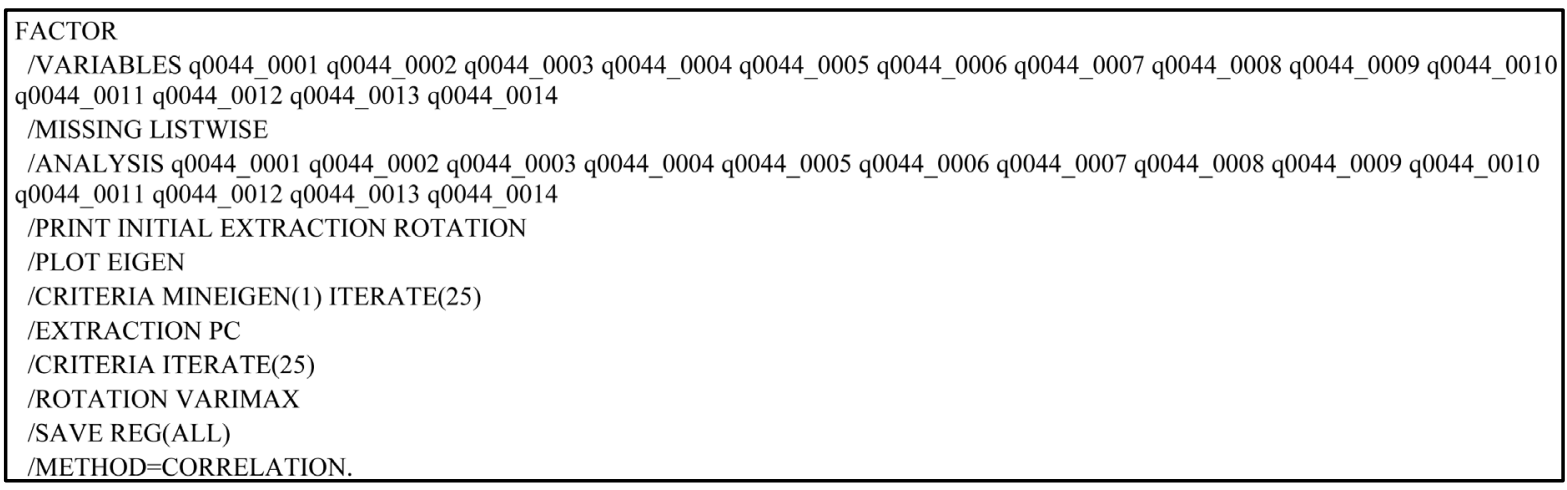

Figure 4. The commands.

The variables (q0044_001, q0044_002, etc.) correspond are illustrated in the matrix of rotated components, that is to say:

I am blackberries informed than non-celiac sufferers on products with the crossed grain symbol;

I avoid social events (parties, hor d'ouerves, etc.) where I may not be Able to control the food served;

The way in cui food is prepared is important for my diet (style);

Generally I consider myself to be careful about my diet (e.g. vegetarian, vegan, etc.);

Eating gluten-free food seriously limits my choices;

I'm distracted when I'm eating;

I eat away from home only if I know the owner of the restaurant;

Being a celiac sufferer makes interpersonal relations difficult for me;

My diet (style) influences the type of employment or job I chose or would like;

I have difficulty finding restaurants That serves food for celiac sufferers;

I go out with friends less since I discovered I was a celiac sufferer;

I spend most of my time thinking about how and where to eat;

I cook food alone;

I eat at home Because it's safer. 
By reading the graphic on self-values defined in decreasing order, we decided to consider the first two components (Figure 5), supporting Harman's concept [16] according to whom only the components with the highest characteristic values compared to the point in which inertial descent begins should be considered (Table 1).

Therefore the two most influential factors are, for the first component, eating gluten-free greatly limits my food choices (0.656), while for the second component it is fundamental to eat away from home only if you know the owner of the restaurant (0.786).

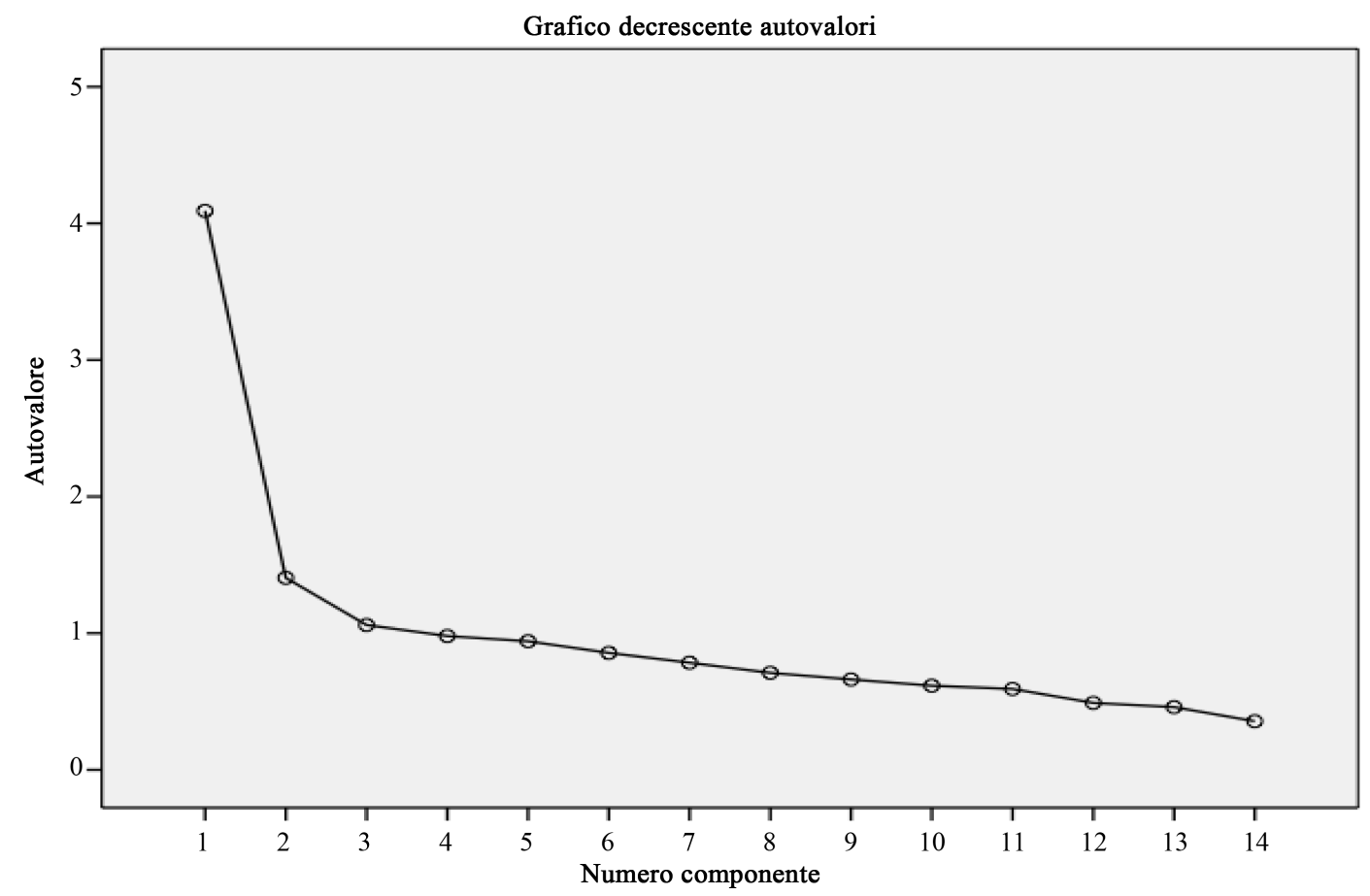

Figure 5. Graphic on self-values defined in decreasing.

Table 1. Total variance explained.

\begin{tabular}{|c|c|c|c|c|c|c|c|c|c|}
\hline \multirow{2}{*}{ Component } & \multicolumn{3}{|c|}{ Initial eigenvalues } & \multicolumn{3}{|c|}{ Weights of the factors not rotated } & \multicolumn{3}{|c|}{ Weights of the factors rotated } \\
\hline & Total & \% variance & $\%$ cumulative & Total & \% variance & \% cumulative & Total & \% variance & $\%$ cumulative \\
\hline 1 & 4.091 & 29.224 & 29.224 & 4.091 & 29.224 & 29.224 & 3.011 & 21.510 & 21.510 \\
\hline 2 & 1.405 & 10.036 & 39.260 & 1.405 & 10.036 & 39.260 & 1.980 & 14.146 & 35.656 \\
\hline 3 & 1.060 & 7.571 & 46.831 & 1.060 & 7.571 & 46.831 & 1.565 & 11.175 & 46.831 \\
\hline 4 & 0.980 & 6.997 & 53.829 & & & & & & \\
\hline 5 & 0.941 & 6.722 & 60.551 & & & & & & \\
\hline 6 & 0.856 & 6.113 & 66.664 & & & & & & \\
\hline 7 & 0.784 & 5.600 & 72.264 & & & & & & \\
\hline 8 & 0.710 & 5.070 & 77.334 & & & & & & \\
\hline 9 & 0.661 & 4.725 & 82.059 & & & & & & \\
\hline 10 & 0.616 & 4.397 & 86.456 & & & & & & \\
\hline 11 & 0.592 & 4.227 & 90.683 & & & & & & \\
\hline 12 & 0.490 & 3.499 & 94.183 & & & & & & \\
\hline 13 & 0.459 & 3.278 & 97.461 & & & & & & \\
\hline 14 & 0.356 & 2.539 & 100.000 & & & & & & \\
\hline
\end{tabular}

Extraction method: Principle component analysis. 
Now we can discuss the rotated components matrix posing the various aspects of the following question:

"How correct are the following statements in your opinion?"

The source matrix is as follows with Varimax rotation, Kaiser normalisation, where rotation has reached the convergence criteria in 5 loops.

Of the two groups that emerge the first could be defined "the solitary apprehensive" as all those who find social relations, as celiac sufferers, difficult. In fact, the "explained variance percentage" is a good $29 \%$ on a total of $46.8 \%$ practically more than half the total of the two overall components extracted (Table 2).

The second group explains that $10 \%$ of the $46.8 \%$ variance total are those who we have defined "careful and aware of the risks”, i.e. those who don't give up anything, but pay particular attention to their diet.

In fact, if we correlate what has emerged from this second component with the differentiations in the Analyse des Données the fact is further confirmed that most minors and elderly are particularly careful about their diet and being a celiac sufferer does not alter their way of life, or at least they get used to it and it isn't a problem.

Lastly, we will present a second analysis also conducted using the pca in which attention is placed on the behaviour closely correlated to diet which was shown in the last month.

SPSS commands used are as follows (Figure 6):

The variables (q0045_001, q0045_002, etc.) correspond are illustrated in the matrix of rotated components, that is to say:

When I go into a grocery store I'm composed;

The thought of food worries me;

My food choices are conditioned by my personal health worries;

The taste of food is an important quality when I purchase food;

I am willing to identify alternative ways of buying food for celiac sufferers (e.g. internet, big warehouses);

Paying attention to the food I eat is a problem I worry about for more than 1 hour a day;

Sometimes I eat food I shouldn't eat;

I feel my mood influences my dietary habits;

At the moment, I eat alone at mealtimes.

In this case, compared to the previous one, three components were maintained, since the second and third influence in equal measure the variance percentage explained, $12.9 \%$ for the second component and $12.2 \%$ for the third (Table 3). Also in this case, the Varimax rotation method with Kaiser normalisation was used where rotation had reached the convergence criteria in 5 loops (Figure 7).

Table 2. Matrix of components rotated.

\begin{tabular}{|c|c|c|}
\hline Matrix of components rotated & 1 & 2 \\
\hline I am more informed than non-celiac sufferers on products with the crossed grain symbol & 0.105 & -0.125 \\
\hline I avoid social events (parties, hor d'ouerves, etc.) where I may not be able to control the food served & 0.258 & 0.722 \\
\hline The way in which food is prepared is important for my diet (style) & 0.040 & 0.221 \\
\hline I consider myself to be generally careful about my diet (e.g. vegetarian, vegan, etc.) & -0.078 & 0.160 \\
\hline Eating gluten-free seriously limits my food choices & 0.656 & 0.034 \\
\hline I'm distracted when I'm eating & 0.411 & -0.063 \\
\hline I eat away from home only if I know the owner of the restaurant & 0.015 & 0.786 \\
\hline Being a celiac sufferer makes interpersonal relations difficult for me & 0.680 & 0.389 \\
\hline My diet (style) influences the type of employment or job I chose or would like & 0.539 & 0.240 \\
\hline I have difficulty finding restaurants that serve food for celiac sufferers & 0.619 & 0.024 \\
\hline I go out less with friends since I discovered I was a celiac sufferer & 0.624 & 0.503 \\
\hline I spend most of my time thinking about how and where to eat & 0.654 & 0.198 \\
\hline I cook food alone & 0.381 & 0.056 \\
\hline I eat at home because it's safer & 0.476 & 0.491 \\
\hline
\end{tabular}


Table 3. Total variance explained.

\begin{tabular}{|c|c|c|c|c|c|c|c|c|c|}
\hline \multirow{2}{*}{ Component } & \multicolumn{3}{|c|}{ Initial eigenvalues } & \multicolumn{3}{|c|}{ Weights of the factors not rotated } & \multicolumn{3}{|c|}{ Weights of the factors rotated } \\
\hline & Total & Variance \% & Cumulative \% & Total & Variance \% & Cumulative \% & Total & Variance \% & Cumulative \% \\
\hline 1 & 2.774 & 30.826 & 30.826 & 2.774 & 30.826 & 30.826 & 2.372 & 26.352 & 26.352 \\
\hline 2 & 1.164 & 12.935 & 43.761 & 1.164 & 12.935 & 43.761 & 1.375 & 15.281 & 41.633 \\
\hline 3 & 1.102 & 12.243 & 56.003 & 1.102 & 12.243 & 56.003 & 1.293 & 14.371 & 56.003 \\
\hline 4 & 0.865 & 9.612 & 65.615 & & & & & & \\
\hline 5 & 0.798 & 8.862 & 74.477 & & & & & & \\
\hline 6 & 0.702 & 7.795 & 82.272 & & & & & & \\
\hline 7 & 0.654 & 7.268 & 89.540 & & & & & & \\
\hline 8 & 0.542 & 6.021 & 95.561 & & & & & & \\
\hline 9 & 0.399 & 4.439 & 100.000 & & & & & & \\
\hline
\end{tabular}

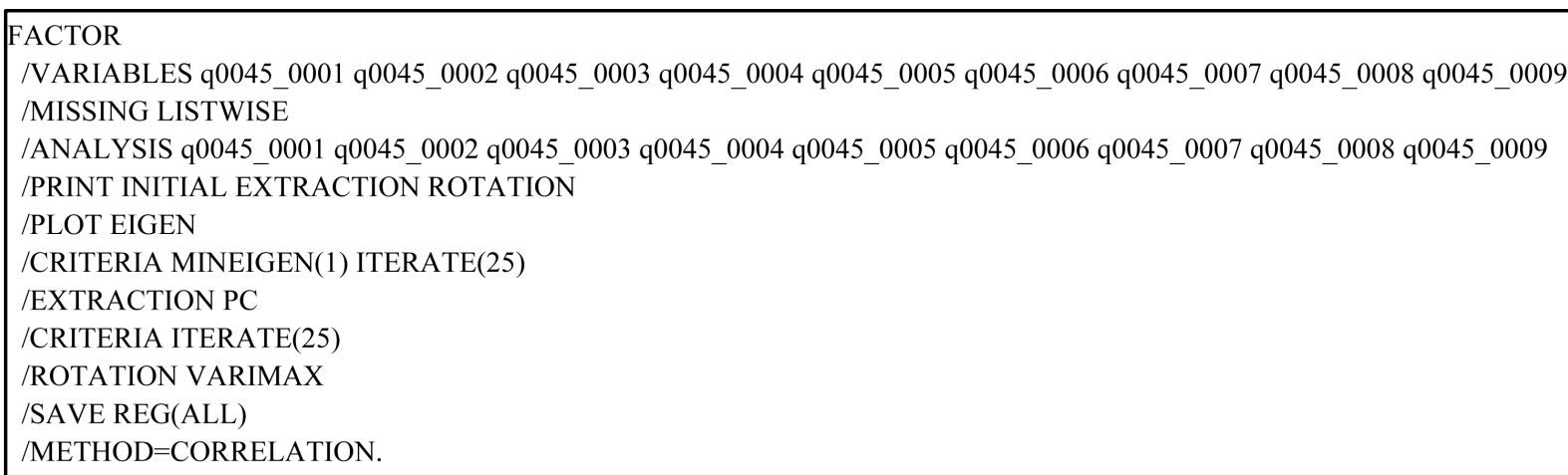

Figure 6. The commands.

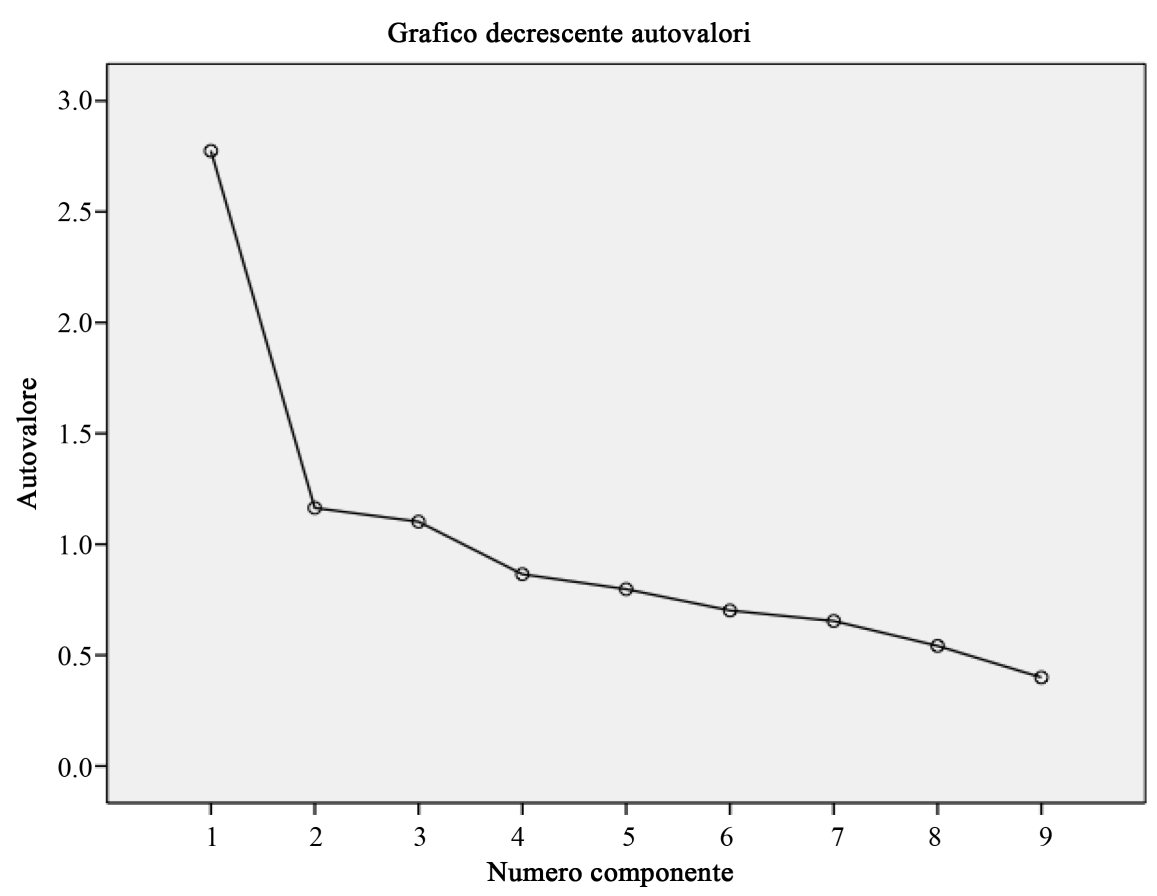

Figure 7. Graphic on self-values defined in decreasing. 
Three groups emerge, the first we have defined as the "tormented" with an explained variance of $30 \%$ on a total equal to 56\%, followed by the "couldn't care less" and the "careful food lovers" both with an explained variance around $13 \%$ compared to the $56 \%$ total (Table 3 ).

Now we'll explain the specific details of the three groups (Table 4): the tormented are those who pay most attention to their dietary habits, where eating becomes a problem and they worry about food for over an hour a day. Their dietary choices are influenced by their health and when they go food shopping they are confused. General discomfort is therefore revealed.

The second group called the "couldn't care less" are those who allow themselves some dietary transgression and they believe their wellbeing is directly influenced by their dietary habits, therefore compared to the previous group they live their illness with less apprehension.

Lastly, for food lovers, the taste of food is the most important quality, particularly when they do the shopping, which in fact influences what they will eat the following days. There are also those who buy food for celiac sufferers also through alternative sales channels (for example internet, big warehouses).

\section{Conclusions}

From the two initial assumptions formulated in the introduction we can be satisfied with both.

The first linked to comprehension of dietary compliance provided us, thanks to the Analyse des Données, with a scenario not in the least taken for granted, particularly for specialists [17], based on which the main distinction is found in the different lifestyles: young adults are those linking risk to stigma [18], where it is preferred to transgress than reveal their medical condition; instead, for minors the overall picture is better. Transgression is almost non-existent because the risk is almost non-existent; adults take responsibility for their medical condition, resulting in greater awareness of risks, i.e. it leads to less dietary transgression, but at the same time complicates relations with colleagues, and lastly, the elderly have the best social relations, especially among friends [19]. Instead, the contribution of the pca enabled us to go beyond the profiles relating to the phases of life and understand the diet and practices related to the gluten-free diet giving different behavioural groups, distinguished among those who love food, couldn't care less and the tormented.

The second assumption refers to the clearly methodological aspects, in particular based on the web-survey, allowing us to have an ex-post representative sample of the reference universe and moreover this technique was in fact unrestrictive to the possibilities of conducting the analysis with the pca and the Analyse des Données. Based on the quality of the data, compared with the interview trend between the two surveys, the first consideration refers to the digital divide phenomenon: for the complete interviews, following the measures proposed by the AAPOR, we can highlight a sensitive variance of 6.4 percentage points in disfavour of the second study, which in light of the percentage of partial interviews also increased by 5.3 points and abandonment that passed from $2.9 \%$ to $4.2 \%$, it is easy to assume that among those taking part in the second survey there are some new people, i.e. those who didn't take part in the 2011 study. And yet, despite the reference theories, you are reminded

Table 4. Matrix of components rotated.

\begin{tabular}{|c|c|c|c|}
\hline \multirow{2}{*}{ Matrix of components rotated } & \multicolumn{3}{|c|}{ Component } \\
\hline & 1 & 2 & 3 \\
\hline When I go into a grocery store I'm composed & 0.650 & 0.199 & -0.078 \\
\hline The thought of food worries me & 0.834 & 0.114 & 0.071 \\
\hline My food choices are conditioned by my personal health worries & 0.715 & -0.132 & 0.256 \\
\hline The taste of food is an important quality when I purchase food & 0.121 & -0.047 & 0.770 \\
\hline $\begin{array}{l}\text { I am willing to identify alternative ways of buying food for celiac sufferers } \\
\text { (e.g. internet, big warehouses) }\end{array}$ & 0.026 & 0.120 & 0.743 \\
\hline Paying attention to the food I eat is a problem I worry about for more than 1 hour a day & 0.724 & 0.247 & 0.087 \\
\hline Sometimes I eat food I shouldn’t eat & -0.096 & 0.804 & 0.021 \\
\hline I feel my mood influences my dietary habits & 0.371 & 0.555 & 0.250 \\
\hline At the moment, I eat alone at mealtimes & 0.234 & 0.523 & -0.044 \\
\hline
\end{tabular}


that sample subjects using the internet can encounter problems relating to the digital divide [20]. In relation to this, we verified that no major problems arose to exclude specific age groups from the study, such as the elderly, who make up $31 \%$ of the sample. Considering the analysis and response rates, we can therefore confirm that the web-survey provided us with data as valid as that of paper \& pencil questionnaires, a new tool for the toolbox to use that is valid in web 2.0 contexts.

What emerged is not at all obvious as it breaks the prevailing ideology indicated in healthcare on compliance to the diet and eating habits adopted by celiac, which they considered adherent to treatment with significantly higher percentages that roam over 50\% [21]-[23]. In our study, however, giving the floor directly to the celiac and not inferring adherence to treatment by the statements of the protagonists in the medical field, it was found that the celiac admit they do not trust the doctor his transgression, a problem of no small importance especially in view of the prevailing narrative-based medicin [24]-[26].

Think of the celiac person as a rational actor mean for young adults weigh the different choices available, in order to achieve acceptance and get away as possible from the stigma that involves being sick [27], how much more lifestyle opens new horizons much greater the responsibility [28]. Surely in times linked to the choice of the steps to be taken, that is with respect to compliance to the diet, the young celiac weighs the costs and benefits of potential actions to be taken, from what emerges from the study, although the interpretation of the self and social processes [29], is winning a vision linked to a more rationality of economic-social: I prefer to transgress deliberately and not reveal my disease condition in favor of a social and professional acceptance.

Often we talk about the medicalization of everyday life [30] especially in the case of chronic diseases, an aspect that can be extended to celiac, who buy thanks to tickets provided by the National Health Service glutenfree foods directly to the pharmacy, this form of purchase can make the meal can be lived and/or exchanged, not as a time for socializing and sharing, but as to a cure, approaching the idea that foods are transformed into real "medicine".

\section{About the Authors}

Cleto Corposanto is a Full Professor of Sociology (SPS/07) at the University Magna Graecia-Catanzaro, previously worked at the University of Trento (Italy).

He is Chairman of the Technical Committee for the Ba and Ma courses in Social Work and Scientific Director of CRISP-Centre for Interdisciplinary Research on Health Systems and Welfare Policies at the "Magna Græcia” University of Catanzaro (Italy).

He is the author of about two hundreds of scientific publications (in Italian, English and German), including several monographs on topics of social research methodology, social services and health, the sociology of health and illness, planning and social evaluation.

Among his research interests:

- Methodology and techniques of social research, on the side of their integration.

- Quality assessment of health and social services.

- Citizen's participation in the processes of construction of health policy and social issues.

- Sociology of health and medicine, capital and health; social implications of the disease.

- Statistical methods, with particular reference to issues of multiple classification.

Beba Molinari PhD in sociology at the University of Genoa, where she collaborates since 2004. She studies Sociology, Methodology and Techniques of Social Research at the Faculty of Educational Sciences.

From 2008 to 2011 Phd student in the Department of Educational Sciences; since 2008 she has collaborated with the research center "Cenpro" in the Faculty of Economics in the same university, where she specializes in data analysis into the Third Sector. Since 2004 till now she wrote four book chapters and other four essays on Third sector and Voluntary and the Celiac Disease with particularly attention for the methodology of social research and evaluation of the local and regional policies.

She participated with the University of Genoa and Liguria Region in four European projects in five years (Leonardo, Equal, Youth in Action, Central Europe).

Susanna Neuhold She coordinate at national level the communication and educational programmes on diet and nutrition of the Italian Coeliac Association (AIC) for coeliac people and their families. Editor of many articles and texts on food safety and allergens management for food producers and caterers. Speaker in many courses, seminars, conventions on food safety, allergen management and nutritional education of people with 
coeliac disease. Member of the Technical Commission on Catering sector of the Italian National Standardisation Organization (UNI) on behalf of the AIC Member of the Technical Committee of the European Licensing System of the Association of European Coeliac Societies (AOECS) on behalf of the AIC AOECS Delegate on behalf of the AIC.

\section{References}

[1] Christensen, A.J. (2004) Patient Adherence to Medical Treatment Regimens. Yale University Press, New Haven, 3.

[2] American Association for Public Opinion Research (2006) Standard Definitions: Final Dispositions of Case Codes and Outcomes Rates for Survey. 4th Edition, AAPOR, Lenexa.

[3] (2014) Social Media in Public Opinion Research: Report of the AAPOR Task Force on Emerging Technologies. Public Opinion Research, Lenexa (KS). Corposanto C. (Corposanto, C. (2002) Il ciclo statistico della ricerca sociale, FrancoAngeli, Milano. (2011) Celiachia, malattia sociale, FrancoAngeli, Milano.

[4] Palumbo, M. and Garbarino E. (2004) Metodologia della ricerca sociale. Dalla interrogazione alla relazione, Franco Angeli, Milano.

[5] Marradi, A. (1981) Misurazione e scale: Qualche riflessione e una proposta. Quaderni di Sociologia, 21, 117-132.

[6] Cipolla C. (2004) Manuale di sociologia della salute. Vol. I, Teoria, Franco Angeli, Milano.

[7] Giddens, A. (1990) The Consequences of Modernity. Stanford University Press, Stanford. $\square$

[8] Luhmann, N. (1991) Soziologie des Risikos. Walter de Gruyter GmbH \& Co, Berlin.

[9] Ministero della Salute (2011-2013) Relazione annuale al parlamento sulla celiachia. Anno 2011-2013, Roma.

[10] Benzécri, J.P. (1969) Statistical Analysis as a Toll to Make Patterns Emerge from Data. In: Satosi, W., Ed., Methodologies of Pattern Recognition, Academic Press, New York, 35-74. http://dx.doi.org/10.1016/B978-1-4832-3093-1.50009-2

[11] Benzécri, J.P. and Benzécri, F. (1984) L’analyse des Données. Analyse des Correspondance \& Classification Exposé Elémentaire. Dunod, Paris.

[12] Di Franco, G. (2006) Corrispondenze multiple e altre tecniche multivariate per variabili categoriali. Franco Angeli, Milano.

[13] Capecchi, V. (1967) Metodologia e ricerca nell’opera di Paul Lazarsfeld.

[14] Ricolfi, L. (1992) Helga. Nuovi principi di analisi dei gruppi. Angeli, Milano.

[15] Di Franco, G. (2005) EDS: Esplorare, descrivere e sintetizzare i dati. Franco Angeli, Milano.

[16] Harman, H.H. (1967) Modern Factor Analysis. University Press of Chicago, Chicago.

[17] Wolters, V.M. and Wijimenga, C. (2008) Genetic Background of Celiac Disease and Its Clinical Implications. American Journal of Gastroenterology, 103, 190-195. http://dx.doi.org/10.1111/j.1572-0241.2007.01471.x

[18] Goffman, E. (1961) Encounters: Two Studies in the Sociology of Interaction. Bobbs-Merrill, Oxford.

[19] Lee, A. and Newman, J. (2003) Celiac Diet: Its Impact on Quality of Life. Journal of the American Dietetic Association, 103, 1533-1535. http://dx.doi.org/10.1016/j.jada.2003.08.027

[20] Vehovar, V. and Lozar, M.K. (2008) Overview: Online Surveys. In: Fielding, N., Lee, R.M. and Blank, G., Eds., The SAGE Handbook of Online Research Methods, SAGE, London, 177-194.

[21] Koppen, E.J., Schweizer, J.J., Csizmadia, C.G.D.S., Krom, Y., Hylkema, H.B., van Geel, A.M., et al. (2009) LongTerm Health and Quality of Life Consequences of Mass Screening for Childhood Celiac Disease: A 10-Year FollowUp Study. Pediatrics-Official Journal of the American Academy of Pediatrics, 123, e582-e588. http://dx.doi.org/10.1542/peds.2008-2221

[22] Cranney, A., Zarkadas, M., Graham, I.D. and Switzer, C. (2003) The Canadian Celiac Health Survey-The Ottawa Chapter Pilot. BMC Gastroenterology, 3, 8. http://dx.doi.org/10.1186/1471-230X-3-8

[23] Ciacci, C., D’Agate, C., De Rosa, A., Franzese, C., Errichiello, S., Gasperi, V., Pardi, A., Quagliata, D., Visentini, S. and Greco, L. (2003) Self-Rated Quality of Life in Celiatic Disease. Digestive Diseases and Sciences, 48, $2216-2220$. http://dx.doi.org/10.1023/B:DDAS.0000004530.11738.a2

[24] Brody, H. (1987) Stories of Sickness. Yale University Press, New Haven.

[25] Baer, H.A. (1987) Encounters with Biomedicine: Case Studies in Medical Anthropology. Gordon and Breach Science Publishers, New York.

[26] Good, B.J. and Del Vecchio-Good, M.J. (2000) “Parallel System”: Medical Anthropology and Medical Sociology. In: Bird, C.E., Conrad, P. and Fremont, A.M., Eds., Handbook of Medical Sociology, Prentice Hall, New Jersey, xi-516. 
[27] Maturo, A. (2007) Sociologia della malattia. Franco Angeli, Milano.

[28] Melucci, A. (1991) Il gioco dell’io. Il cambiamento di sé in un società globale. Feltrinelli, Milano.

[29] Lash, S. (1993) Reflexive Modernization: The Aesthetic Dimension. Theory, Culture and Society, 10, 1-23. http://dx.doi.org/10.1177/026327693010001001

[30] Illich, I. (1973) Limits to Medicine. Medical Nemesis: The Expropriation of Health. Marion Boyars Publisher Ltd., London. 